\title{
Vestidos-objeto de Olly Reinheimer: a veiculação na mídia impressa sobre a exposição realizada no MAM-RJ em 1969
}

Olly Reinheimer's object-dresses: repercussion of the exhibition held at MAM-RJ in 1969 on print media

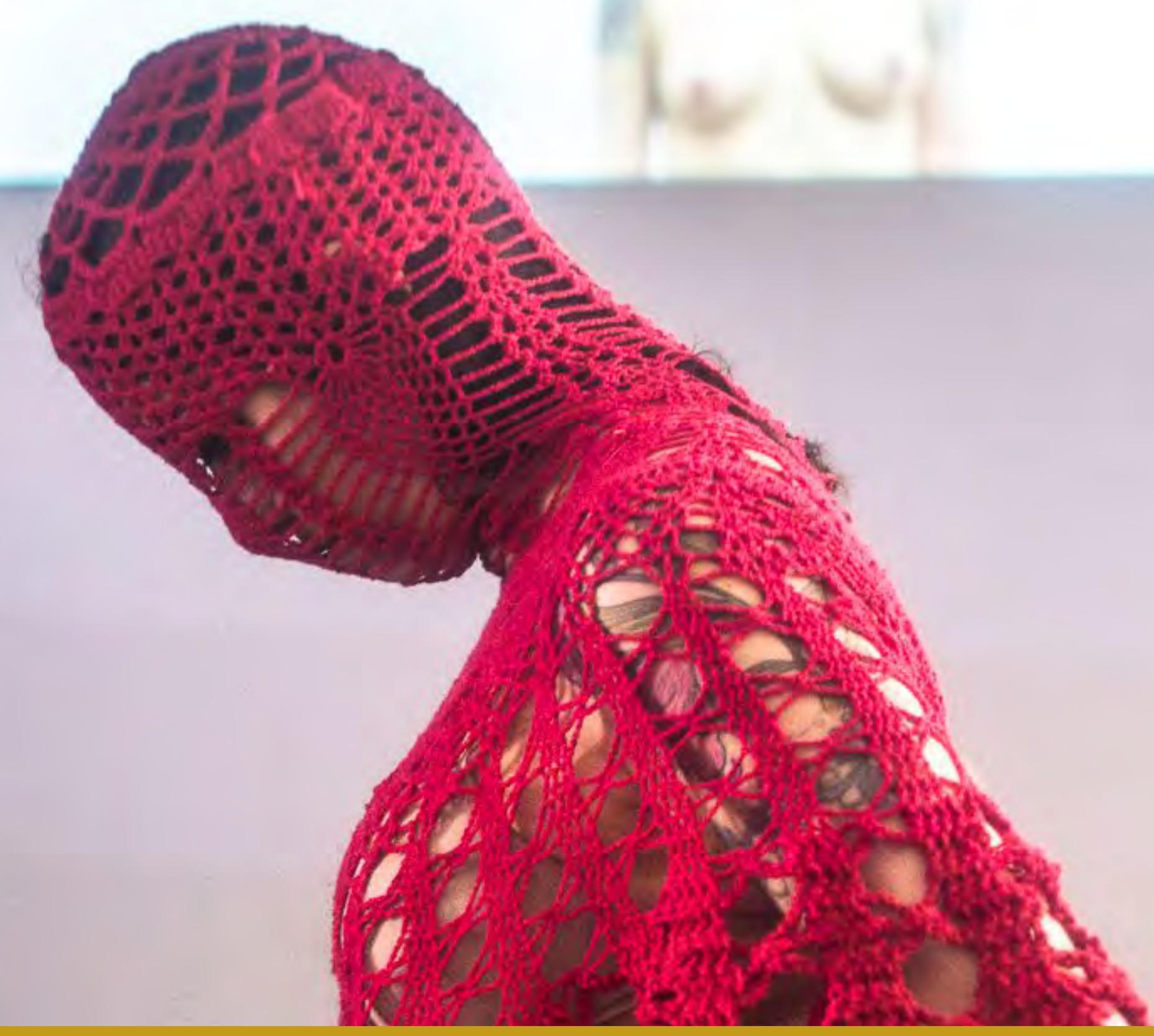




\section{Carolina Morgado Pereira ${ }^{1}$}

ORCID: https://orcid.org/0000-0002-0664-7687

[resumo] Este artigo visa analisar e comparar as distintas críticas artísticas e veiculações sobre a exposição Vestidos-objeto ocorrida no MAM-RJ, em 1969, e a disparidade das opiniões na leitura do evento. A mostra de Olly Reinheimer produz uma contradição entre os espectadores, críticos de arte e jornalistas, que irão publicar conteúdos diferenciados para cada segmento de público (artes, feminino ou entretenimento) na mídia impressa da época. A análise dos discursos e imagens publicados é realizada nos periódicos $O \mathrm{Dia}$ (RJ), Correio da Manhã (RJ), Jornal do Brasil (RJ), Última Hora (RJ) e Jornal do Commercio (RJ), a partir do embasamento teórico-artístico de Argan (1994; 2005; 2006) e também dos pressupostos teóricos sobre cultura visual e material de Ulpiano Toledo Bezerra de Meneses (2003).

\section{[palavras-chave] Olly Reinheimer: MAM-RJ. Arte têxtil. Arte vestível.}

[abstract] This article aims to analyze and compare the different artistic criticisms and repercussions about the exhibition that took place in MAM-RJ in 1969, and the disparity of opinions regarding the event. Olly Reinheimer's exhibition produces a contradiction in viewers, art critics, and journalists who will publish different content for each audience segment (arts, women, or entertainment) in print media at the time. The analysis of the discourses and published images is carried out in the newspapers O Dia-RJ (1951), Correio da Manhã - RJ (1901-1974), Jornal do Brasil - RJ (1891), Última Hora - RJ (19511991), and Jornal do Commercio - RJ (1827-2016). This article is guided by the theoretical-artistic basis of Argan $(1994,2005,2006)$, as well as the theoretical assumptions about the visual and material culture of Ulpiano Toledo Bezerra de Meneses (2003).

[keywords] Olly Reinheimer. MAM-RJ. Textile art. Wearable art.

Recebido em: 31-01-2019

Aprovado em: 09-06-2019

\footnotetext{
1 Doutoranda em Artes Visuais - Programa de Pós-graduação em Artes Visuais da Escola de Belas Artes da Universidade Federal do Rio de Janeiro. Mestre em Artes Visuais - Programa de Pós-graduação em Artes Visuais da Escola de Belas Artes da Universidade Federal do Rio de Janeiro. Docente do Curso Técnico Pós-médio de Produção de Moda - Fundação de Apoio à Escola Técnica (FAETEC-RJ). E-mail: carolina.morgado.carol@gmail.com. Lattes: http://lattes.cnpq.br/0978957818718523.
} 


\section{Introdução}

O presente artigo analisa e compara os diferentes posicionamentos publicados pela mídia impressa sobre a exposição Vestidos-objeto, de Olly Reinheimer ${ }^{2}$ (1914-1986), realizada no MAM-RJ, em 1969. Postulamos que a variedade de posicionamentos nos conteúdos publicados nos periódicos que analisamos - localizados em diversas seções (artes, feminino ou entretenimento) -destaca o trânsito da produção artística e funcional da obra da artista Olly Reinheimer, enfatizada, então, pelo fluxo de informações e percepções sobre a mostra feita no museu. Os artigos também questionam sua produção e seu local de inserção em áreas não delimitadas no período, como o âmbito das artes e da moda. 0 corpus deste trabalho é composto pelas publicações encontradas no Caderno Feminino, do jornal O Dia (RJ), no jornal Correio da Manhã (RJ), na Revista de Domingo do Jornal do Brasil (RJ) e nas colunas de arte do jornal Última Hora (RJ) e Jornal do Commercio (RJ).

Nos periódicos em que têxteis, vestuários e acessórios são descritos de acordo com a sua fotografia ou a sua ilustração, ressaltam-se as características dessas peças, tal como as observações de jornalistas e colunistas inseridos em seu contexto sociocultural. Ulpiano T. Bezerra de Menezes (2003) considera que há nas premissas da história visual o direcionamento para o âmbito visual da imagem, em "sistemas de comunicação visual, os ambientes visuais, a produção/circulação/consumo/ação dos recursos e produtos visuais”, e principalmente a apreciação da "vida social" desse objeto em um olhar para as transformações históricas. Conforme Menezes, as "imagens não têm sentido em si, imanentes" (MENEZES, 2003, p. 30), visto que é na interação social que ocorre a produção de sentido de valores, para fazê-las atuarem no tempo, no espaço, nos lugares e nas circunstâncias sociais. A imagem é assim um "enunciado" de contextos "situacionais". Desse modo, as imagens veiculadas são consideradas como um objeto material e vivo da realidade social.

Na exposição do MAM-RJ de 1969, um conjunto de elementos que especificam uma cultura local e também evidenciam particularidades do segmento artístico por meio das críticas de arte e suas considerações. Baseados na experiência de visitação da exposição e verificação das obras vistas no MAM-RJ, os jornais salientam as especificidades de Olly em um processo de descrição e observação crítica de seus têxteis e vestuários artísticos.

\section{A exposição Vestidos-objeto no MAM-RJ}

Na década de 1940, a modernização e a industrialização impulsionaram a formação de novos museus voltados para a arte moderna no Brasil, que visavam contato com o público, influenciados por um modelo com atividades didáticas, culturais e sociais. A partir

\footnotetext{
2 Olga Helene Blank (1914-1986) nasceu na Alemanha, Sachsen, Mittweida, no dia 28 de janeiro de 1914. Ela migrou para o Brasil, para a cidade do Rio de Janeiro, em 1936, e casou-se com Werner Siegfried Reinheimer no ano de 1939. Olga adotou o nome 0lly para as suas atividades profissionais e durante toda a década de 1950 frequentou cursos no Museu de Arte Moderna do Rio de Janeiro (MAM-RJ), e seus professores foram: Jhonny Friedlaender e Roberto Delamonica em gravura; Milton Goldring, Ivan Serpa, Zélia Salgado, Santa Rosa e Frank Shaeffer, em pintura; René Leblanc, em desenho; Fayga Ostrower, em composição. Desse modo, sua formação foi fundamentada na base artística moderna.
} 
de 1951, Niomar Moniz Sodré ficou responsável pelo MAM-RJ ${ }^{3}$ com a proposição de apresentar exposições temporárias para atrair grandes fluxos de visitantes, diferentemente do modelo de culto à alta cultura, estabelecendo atividades pedagógicas e exposições itinerantes que exibiam a arte moderna brasileira pelo mundo (SANT'ANNA, 2012).

A direção de Niomar Sodré deu início à formação artística proposta pelo MAM-RJ, integrando o público com a arte. Os primeiros cursos livres do museu tinham em seu corpo docente artistas de destaque premiados, entre eles Ivan Serpa e Milton Goldring, com aulas de pintura, e Margareth Spencer, com aulas de modelagem. Esses cursos foram ministrados primeiramente no prédio do Instituto de Previdência e Assistência dos Servidores do Estado (IPASE) e, depois, na última sede do museu. No ano de 1955, novos cursos foram incorporados, como o Básico de Desenho, com André LeBlanc; Iniciação e Orientação, com Zélia Salgado; Desenho Estrutural e Composição, com Tomás Santa Rosa; e Decoração de Interiores, com Wladimir Alves de Souza. De acordo com Sant’Anna, "a marca do projeto pedagógico do MAM era a profissionalização do artista”, [em um novo olhar para a produção artística da época], "na difusão de políticas museológicas educativas" [que se constroem no pós-guerra] (SANT’ANNA, 2012, p. 7).

0 desejo de uma formação profissional foi impulsionado pela primeira conferência de Max Bill4 , em 30 de maio de 1953 no salão de exposições do museu do prédio do Ministério da Educação e Saúde, em que apresentou a Bauhaus e suas origens e identificou a importância de um projeto pedagógico e da criação da "Escola Superior de Criação" em Ulm, com ênfase sobre a função do artista na sociedade, explicando seu processo de criação da arte concreta com a projeção de seus trabalhos.

Desde sua fundação o MAM-RJ incluía em seus planos o desenho industrial. A Escola Técnica de Criação, onde o ensaio dessa disciplina seria iniciado de forma consequente pela primeira vez no Brasil, não pôde ser concretizada. No entanto, ela serviu de embrião para a Escola Superior de Desenho Industrial do Rio de Janeiro em 1962, que absorveu a essência do plano do MAM que contou com a participação de, entre outros, Max Bill, Tomás Maldonado e Otl Aicher.

Em 1968 o MAM criou o Instituto de Desenho Industrial, organismo destinado inicialmente à promoção e divulgação dos conceitos básicos e dos resultados da atividade, já então em pleno desenvolvimento do Brasil. (IDI - MAM-RJ, 1972)

\footnotetext{
${ }^{3} 0$ Museu de Arte Moderna do Rio de Janeiro, MAM-RJ, em 1948, ocupava as acomodações do Banco Boa Vista, na Candelária, no centro da cidade do Rio de Janeiro. No ano de 1952, o museu mudou para o Palácio Gustavo Capanema, à época sede do Ministério de Educação e Cultura. 0 atual museu, localizado no Parque do Flamengo, teve sua edificação concluída no ano de 1958, com projeto de Affonso Eduardo Reidy e jardins de Burle Marx.

${ }^{4}$ Max Bill (1908-1994) nasceu em Winterthur, na Suíça, foi designer gráfico, designer de produto, arquiteto, pintor, escultor, professor e teórico do Design. Em Zurique, de 1924 a 1927, cursou a academia da Art and Crafts e a Bauhaus na escola de arte e ofícios de Dessau, de 1927 a 1929. Na Escola Suíça de Design Gráfico, foi professor, e, em 1930, corroborou com o conceito de Arte Concreta proposto por Theo Van Doesburg. Entre 1935 e 1953, foi professor e diretor na Escola de Ulm. No Brasil, Max Bill foi reconhecido na I Bienal de São Paulo, em 1951, com o Prêmio Internacional de Escultura. Em 1950, foi convidado por Pietro Maria Bardi para realizar conferências em São Paulo.
} 
Destaca-se a Escola de Ulm como precursora da proposta de cursos profissionais no MAM-RJ, que estarão presentes no projeto de Affonso Eduardo Reidy e que indica o Bloco Escola, local de funcionamento da Escola Técnica de Criação do MAM, que, posteriormente, integraria o desejo de formação do Instituto de Desenho Industrial, fundado em 1969 e reestruturado em janeiro de 1972.

Desde o ano de 1949, relevantes mostras internacionais e de artistas brasileiros renomados enumeram a relação das exposições realizadas na instituição. Apesar dos grandes eventos serem recorrentes nos primeiros anos de existência do museu, os artistas do início do século XX dividem a agenda de programação com pequenas exposições de temáticas diversificadas, que caracterizam o conjunto de exibições. Nelas, evidenciam-se como propostas expositivas temas relacionados a arquitetura, cerâmica, pintura infantil, tapeçaria, arte aplicada, artistas latinos, fotografia, desenho humorístico, cartazes, arte decorativa, desfiles de vestuário, tecidos pintados, pintura oriental, vidro, caricatura, objetos industrializados, aquarela, cenografia, móveis, entre outras - um repertório coerente com as propostas modernas existentes.

No material da exposição de inauguração do MAM-RJ, intitulada Museu de Arte Moderna do Rio de Janeiro Pinturas, Desenhos, Gravuras, realizada em 1952, afirma-se:

Paralelamente a essas tendências centrais, o gosto moderno se interessou pelas artes exóticas, arcaicas, primitivas, populares, infantis, etc. [...] A verdadeira lição de arte moderna foi, porém, a de fornecer os meios de compreender que válido é aquilo que está dotado de valores plásticos e colorísticos, não importando, historicamente, o estilo. (FOLDER MAM-RJ, 1952)

No texto de divulgação da exposição identifica-se o direcionamento do MAM em abrigar e expor produções artísticas e culturais fora do sistema tradicional da arte a fim de que os museus de arte moderna fossem laboratórios e espaços de contato da arte com o público.

Aberta em 6 de agosto de 1969, a exposição Vestidos-objeto, apresentada no Museu de Arte Moderna do Rio de Janeiro (MAM-RJ), sintetiza o trabalho de Olly, artista conhecida por sua produção artesanal e por mesclar diversas técnicas de pintura e gravura em têxteis e vestuários, destacando-se como uma das mostras significativas de sua atividade. Nela, a artista elaborou um happening, com painéis plásticos, música e slides projetados na cena; modelos usavam vestidos pintados à mão ou com padronagens desenvolvidas pela técnica de batik e passavam entre os tecidos pintados e vestuários expostos verticalmente na galeria do MAM-RJ. Produziu, assim, a chamada "roupa-objeto", que permitia explorar a significação do vestuário, de sua matéria-prima têxtil, de seus beneficiamentos artísticos, além da corporeidade e do movimento da modelo. As "roupas-objeto" constituíram uma obra final que integrava a pintura em tecido, a modelagem, a costura e o tridimensional do corpo, agregando valor plástico à sua composição.

A criação dos têxteis e vestíveis de Olly possuem especificidades diversas, desde a apreciação das peças em suportes planares até a interatividade de sua inauguração, com obras circulando, como objetos vestíveis, entre as demais peças na sala de exposição — tudo isso em um período em que a produção de objetos artísticos e funcionais era restrita a alguns 
objetos cotidianos. Assim, verifica-se uma mudança na produção dos objetos em virtude da industrialização, resultando na criação de utilitários com caráter "artístico" (ARGAN, 2010).

Ao mesmo tempo, porém, busca-se adequar o trabalho do artesão ao industrial, ou seja, explorar para fins artísticos o potencial técnico e as possibilidades de difusão da indústria. Nasce assim a moda do mobiliário, do utensílio, da decoração e da indumentária "de arte", que devem proporcionar ao costume, ou seja, à vida cotidiana um caráter "artístico", isto é: de estro e genialidade inventiva. (ARGAN, 2010, p. 445)

Dessa forma, as artes aplicadas possibilitam a criação de objetos com características inventivas e utilitárias. Argan destaca a insurgência das artes "menores" ou "aplicadas" contra a arte "pura", em oposição ao classicismo e a afirmação de uma teoria da arte como "ciência de um fazer humano" (ARGAN, 2005, p. 30). 0 progresso da sociedade estava relacionado ao caráter social da produtividade artística. Assim, a forma era criada por meio da "resolução prática ou utilitária".

A coluna de arte do jornal Última Hora $^{5}$ (Rio de Janeiro, 20/8/1969), de Antonio Bento $^{6}$, e o artigo de Marc Berkowitz ${ }^{7}$ do Jornal do Commercio ${ }^{8}$ (Rio de Janeiro, 21/9/1969), identificam os propósitos vanguardistas da exposição Vestidos-objeto no MAM-RJ. E notam, principalmente, o desenvolvimento do trabalho de Olly, por meio da pintura em tecido, até culminar na criação de vestuário. As críticas de arte de Antonio Bento eram publicadas na versão matutina do jornal delimitada por uma borda, não extensa, que dividia espaço com outras pequenas seções sobre acontecimentos e entretenimento. Localizava-se na quinta página do caderno do jornal, que detinha à época de oito a dez páginas.

\footnotetext{
${ }^{5} 0$ jornal Última Hora (1951-1991), fundado em 12 de junho de 1951 por Samuel Wainer, originalmente carioca, tinha publicações diárias e vespertinas. Periódico popular que introduziu mudanças na produção jornalística, com novas técnicas de comunicação de massa. De apoio a Getúlio Vargas e oposição à classe dirigente, em contraste com a imprensa do período, que criticava o governo getulista. Em 1961, surge a edição nacional impressa no Rio.

${ }^{6}$ Antonio Bento de Araújo Lima (1902-1988), jornalista, escritor e crítico de arte, nasceu em Araruna, na Paraíba, em 1902. Morou no Rio Grande do Norte e iniciou, em 1920, o curso de Direito, em Recife. Em 1934, integrou a equipe do Diário Carioca, em uma seção diária, e na coluna de arte esteve de 1945 a 1965. Também atuou no Diário de São Paulo de 1926 a 1927, um dos precursores do Diário de Notícias em 1930. No jornal última Hora, participou de 1966 a 1970. No Rio de Janeiro, integrou o Conselho Técnico do Museu Nacional de Belas Artes, foi diretor do Teatro Municipal do Rio de Janeiro (1960-1962) e um dos fundadores do MAM-RJ. Participou de bienais, integrou júris dos salões de arte do período. Foi presidente da Associação Brasileira de Críticos de Arte (ABCA) por duas vezes, de 1961 a 1962 e de 1969 a 1974

${ }^{7}$ Marc Berkowitz era de origem russa, em 1928 chega ao Rio de Janeiro. Crítico de arte, em 1944 integra a comissão de arte do Instituto Brasil-Estados Unidos (IBEU). Na década de 1960, participou de salões e bienais de arte do período, assim como em 1969 integrou o júri de premiação na 10a Bienal Internacional de São Paulo.

8 Jornal do Commercio (1827-2016), instituído em 1o de outubro de 1827 por Pierre René François de La Noé, originalmente dedicado a comerciantes. Jornal conservador que na década de1960 apoiou o governo militar.
} 
No artigo há uma foto da inauguração da exposição de Olly também encontrada no espaço de artes plásticas do jornal Diário de Notícias ${ }^{9}$, de 27 de agosto de 1969, assinado por Frederico de Morais: uma modelo com um vestido escrito "MAM", feito exclusivamente para a abertura da exposição. Na coluna do Diário de Notícias não há informações sobre a exposição, somente a imagem com a legenda: "Vestido-cartaz da exposição de Olly Reinheimer no MAM do Rio". Além do vestido criado para o evento, um tecido branco com escritos dos dois lados testemunhava o entusiasmo das pessoas que visitavam o museu, com assinaturas de críticos, artistas e do público. Esse tecido encontra-se atualmente no Acervo Olly e Werner Reinheimer, na casa da família da artista. Na figura 1, observa-se, a foto publicada no Diário de Notícias, na seção de artes plásticas, de Frederico de Morais, de 27 de agosto de 1969, segunda sessão, p. 3.

\section{FIGURA 1 - MODELO COM PEÇA EXCLUSIVA NA EXPOSIÇÃO VESTIDOS-OBJETO (MAM-RJ)}

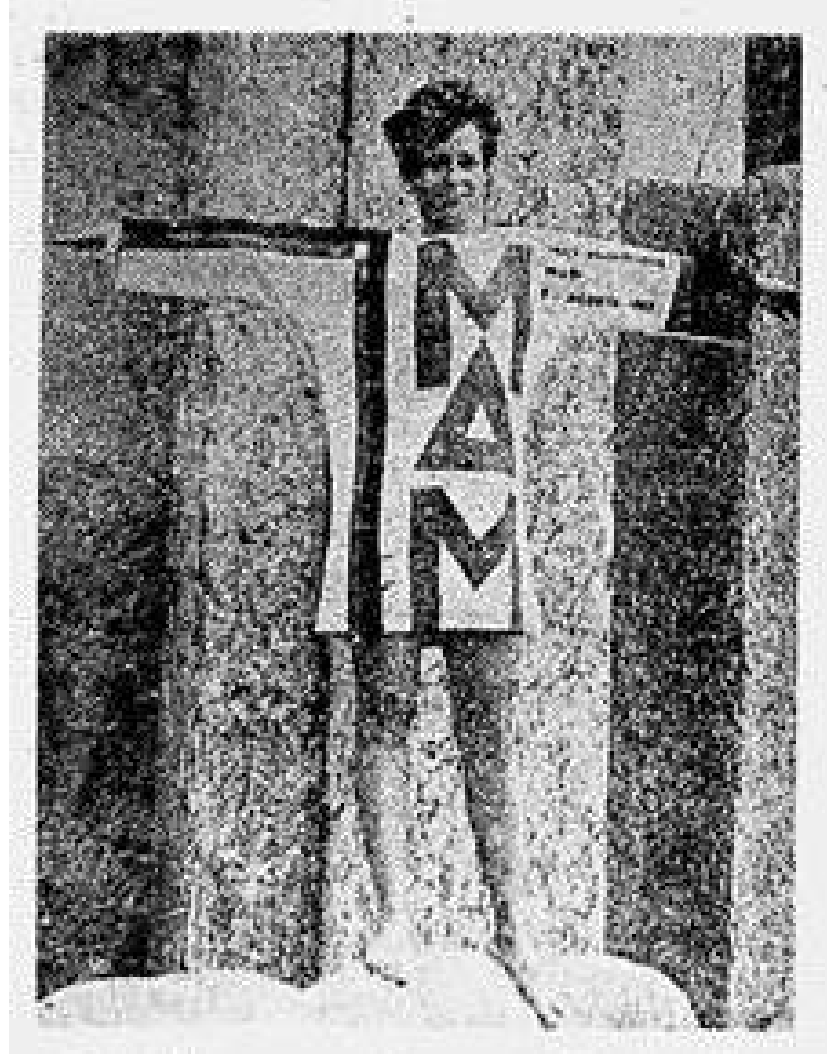

FONTE: MAM-RJ. Arte religiosa. Diário de Notícias, Rio de Janeiro,

27 de agosto de 1969. Foto: Frederico Morais.

\footnotetext{
${ }^{9}$ Diário de Notícias (1930-1974), criado em 12 de junho de 1930 por Orlando Ribeiro Dantas, ficou conhecido por sua proposta de transformação da sociedade. Apoiava a superação de métodos políticos antiliberais. Nos dois governos Vargas, o jornal se posicionou na oposição. Após a morte de Orlando Dantas, assumem o jornal a viúva Ondina Dantas e o filho João Dantas, entretanto uma nova fase inicia-se até o seu declínio. Apesar do apoio a Jânio Quadros, o jornal se opôs ao movimento político-militar. Em 1974, a nova direção de Olímpio Campos não conseguiu apoio do governo e finalizou suas atividades.
} 
0 artigo de Marc Berkowitz encontra-se no suplemento dominical do Jornal do Commercio na seção de artes plásticas, na última página do caderno, próxima à coluna de Roberto Pontual e Mário Barata, ao espaço de notícias, à agenda da semana e à reportagem sobre a X Bienal de São Paulo. O suplemento era o segundo caderno que continha seções sobre literatura, teatro, música e "ritmos jovens".

Tanto na coluna de Antonio Bento quanto na de Berkowitz as dimensões são pequenas se comparadas a outras colunas e reportagens. 0 texto de Antonio Bento para o jornal Última Hora é curto e dinâmico, com conteúdo de arte de acordo com a proposta do período, voltada ao popular; por outro lado, o texto da coluna do Jornal do Commercio, em linguagem mais específica, preocupa-se em introduzir concisamente a produção artística de Olly, inserindo-a nesse cenário com sua análise, bem como ressalta a adequação do trabalho da artista à proposta de vanguarda do MAM-RJ. Em sua introdução, Berkowitz afirma:

\footnotetext{
Sempre à procura de novos meios de expressão, de novas técnicas, de novos materiais - de uma linguagem própria e original. Olly fez cerâmica, excursionou pela pintura e pela gravura, está planejando joias. Mas nos últimos anos tem se dedicado sobretudo aos tecidos pintados, que ela leva à consequência final: o vestido. (BERKOWITZ, Jornal do Commercio, Artes Plásticas, 1969, p.8)
}

Dessa forma, o vestido-objeto é resultado do caminho trilhado por Olly em relação à sua experimentação artística quanto ao estudo da tridimensionalidade corporal. Berkowitz afirma que Olly pertencia à classe dos artistas eternamente insatisfeitos, em busca de novas técnicas e materiais, criando, assim, outras possibilidades de aprimorar suas produções, entre cerâmica, pintura, gravura, tecelagem, joias. Nessa fase, Olly também realizou produções limitadas, tal como na gravura "os múltiplos", edições numeradas de seus vestidos feitos segundo o processo de serigrafia.

A respeito do trabalho de Olly, Marc Berkowitz afirma em sua coluna do Jornal do Commercio (RJ) de 21 de setembro e no Dicionário das Artes Plásticas no Brasil, em 1969:

Não se trata de arte aplicada no sentido algo limitativo da palavra. Através da pintura em tecidos. Olly conseguiu chegar ao vestido-objeto com a intenção mais contemporânea da arte. Olly não se contenta em pintar um tecido, obedecendo algumas das técnicas mais conhecidas, nas quais a criação se limita à seleção de cores, desenhos e padronagens. Olly dominou todas as técnicas, desde o batik até a pintura com pincel sem esquecer o tear - para depois inventar as técnicas dela. Ela estuda todas as tintas e materiais para aproveitar o que antes nunca fora aproveitado. Ela se inspira em formas e ideogramas pré-colombianos, índios, orientais - sem deixar de inventar os seus desenhos próprios - para chegar à tão difícil e tão rara transubstanciação que transforma a arte autenticamente popular em algo universal. (BERKOWITZ, 1969, p. 395)

A concepção da artista em relação aos seus objetos foi chamada de antiarte, porém a expositora contrapõe essa denominação em fala publicada na coluna de Antonio Bento, uma vez que, acredita no trabalho artesão do artista fundamentado na elaboração de objetos 
cotidianos. 0 crítico Quirino Campofiorito ${ }^{10}$ destaca em sua coluna de artes plásticas de $O$ Jornal $^{11}$ (Rio de Janeiro, 6/8/1969) que essa acepção de Olly enaltece a costura individual como técnica e ressalta a realização dessa execução por um artista, criador ou artesão, em um conceito de modernidade baseado na criação de objetos com características artísticas e funcionais. Do mesmo modo, Argan (2005) destaca que as diversas possibilidades de superfície e texturas presentes em diferentes materiais e o trabalho - de um fazer, de uma técnica desenvolvida para um resultado esperado, em um espaço-tempo contínuo - abrem uma nova perspectiva para a contemplação da criação.

A coluna de artes plásticas do jornal do dia 6 de agosto de 1969, de Quirino Campofiorito, localiza-se na página 3 do segundo caderno, ao lado do espaço de literatura intitulado "Jornal Literário", de Valdemar Cavalcanti, abaixo das colunas de teatro de Brício de Abreu, de música de Ayres de Andrade e de "Noites Cariocas", de Titto Santos. No dia 14 de agosto de 1969, Campofiorito publica novamente mais um texto sobre a exposição de Olly Reinheimer no MAM, situado na página 4, no segundo caderno, intitulado Você, com conteúdo para o público feminino e entretenimento em geral. Campofiorito afirma que Olly não procura fazer moda. Segundo a artista:

Fazer moda, mas sim criar especialmente para o tipo de mulher que me procura. Esforço-me por harmonizar meu desenho com a qualidade do tecido, e tento inventar sem ter a pretensão de ser modista. Os meus modelos são sempre simples e, creio, cômodos também. Parece-me importante que a mulher se sinta bem na roupa. Minha preocupação é conseguir o adequado para cada tipo e idade.

A moda pode ser ridícula quando não está de acordo com a pessoa que a usa, e por isto acho indispensável que a costura individual continuará, pois é quando o costureiro se preocupa com sua cliente, procurando sempre conhecê-la melhor para criar certo e sublinhar a forma bem conhecida, e possivelmente esconder melhor o que não deve aparecer.

A costura individual é e será sempre importante, pois toda a primeira peça é feita por um artista, criador ou artesão, e posteriormente reproduzida em série nas medidas estândardes, para que a compra se faça acessível. (CAMPOFIORITO, 1969, Caderno Você, Artes plásticas, p.4)

\footnotetext{
${ }^{10}$ Quirino Campofiorito (1902-1993), pintor, crítico de arte, professor e gravador. Na Escola Nacional de Belas Artes (ENBA) iniciou seus estudos, em 1920. Desde 1926, há registros de críticas de arte no jornal $A$ reação de Campofiorito. Em 1944, começa a atuar nos Diários Associados, como correspondente no Diário da Noite. Em 1948, passa a trabalhar no 0 Jornal, principal veículo do grupo Associados, na coluna de arte, escrevendo para um público interessado, impulsionado pela criação de novos museus no fim da década de 1940 .

11 O Jornal (RJ, 1919-1974) foi criado em 1919 por Renato de Toledo Lopes, com publicações diárias. Em 1924, foi adquirido por Francisco Assis Chateaubriand Bandeira de Melo (1892-1968), sendo o primeiro jornal integrante da futura cadeia intitulada "órgão líder dos Diários Associados". Em seu início, O Jornal dedicou-se a assuntos literários e científicos e sua redação reunia um grupo de profissionais fora do circuito jornalístico. O Jornal apoiou o governo militar, entretanto, com o falecimento de Assis Chateaubriand em 1968 a crise na imprensa carioca, o periódico encerrou suas atividades em 1974 .
} 
Campofiorito declara estar de acordo com as considerações de Olly. Tanto sua criação "em forma de vestido" quanto sua decoração de tecidos, evidencia sua produção decorativa, além de seus aspectos funcionais. Também reitera que no contexto da modernidade o termo "vestido-objeto" é adequado. Para o crítico, o vestido é feito para produção em massa, e sempre será um objeto, embora a proposta estética seja indispensável. Apesar disso, Campofiorito não concorda com o desfile de inauguração e o happening feito com modelos entre as obras planares expostas. Considerou o evento um "excessivo barulho musical", e o desfile com as jovens e seus vestidos uma "passarela de beleza", em que elas incitavam mais atenção que os vestidos que usavam, em um exemplo de "modernidade feminina". Entretanto, o crítico ressalta a atividade criativa de Olly e seu compromisso com uma proposta artística. 0 trabalho prático e o processo de uso de suporte dos tecidos com concepção moderna de pintura e composição são aceitos e reconhecidos por Campofiorito, no entanto, a proximidade dos códigos, as linguagens de exibição das peças em formato de desfile e a vanguarda artística o incomodam.

A diversidade do trabalho da artista apresenta-se em três momentos da exposição, seriados conforme seus últimos anos de trabalho. Entre eles estão: roupas de temas peruanos, com referências de formas e ideogramas regionais; vestidos com tecidos de algodão; e a série Carajás, em tecido de algodão com pinturas e colorido terroso. Esta última faz referência aos bonecos de barro dos índios Carajás, com o propósito de salientar cores e formas da cultura brasileira.

Os críticos Antonio Bento e Marc Berkowitz evidenciam a incipiente moda brasileira. Berkowitz destaca a produção de adaptações da moda internacional e distingue Olly como uma criadora com assinatura e linguagem próprias. Antonio Bento (1969, Última Hora, Artes, p.5) declara que a artista realiza "verdadeiras 'assemblages', utilizando-se de fibras, conchas, caramujos e outras 'bossas' que despertam comentários hostis ou intrigados dos profissionais da alta-costura". A elegância não era um valor para Olly, seu diferencial estava na criação com temáticas brasileiras e latinas em seus têxteis e vestíveis. Campofiorito também acredita na não existência de uma moda brasileira instituída, reconhece no período a presença das adaptações da moda internacional, e evidencia que Olly estaria se aproximando de algo que difere da produção internacional.

A inauguração da exposição Vestidos-objeto é ressaltada no Correio da Manha ${ }^{12}$ (7/8/1969). Nela, destacam-se a "ambientação de Pedro Sayad, projeção de slides de David Zingg, joias de Pedro Correia de Araújo e música eletrônica selecionada por Rogério Coimbra". Trabalharam com Olly na abertura da exposição os já mencionados David Zingg, na fotografia e na direção artística; Pedro Araújo, na criação das joias; Karl Bergmüller, da Bauhaus e da Escola de Desenho Industrial, na coordenação geral; Pedro Sayad, na ambientação. As manequins eram Lúcia Lemos, Maria Teresa, Patrícia Niemeyer, Tânia,

\footnotetext{
12 Correio da Manhã (1901-1974), em 15 de junho de 1901, jornal carioca diário e matutino, é fundado por Edmundo Bittencourt, conhecido por seu influente posicionamento político na sociedade. Paulo Bittencourt integra a equipe do jornal no fim da década de 1910. Niomar Muniz Sodré Bittencourt, a esposa de Paulo, assume a direção do jornal após a morte do marido, em 1963. Em 1969, o jornal foi arrendado para o grupo coordenado por Maurício Nunes de Alencar, o que afasta o periódico de sua concepção liberal, passando a atuar em um novo posicionamento de apoio ao governo. Em 1974, o jornal fecha e encerra suas ocupações profissionais.
} 
Eunice Araújo e Márcia Rodrigues. Na plateia do evento estavam Niomar Moniz Sodré Bittencourt, Vera Mindlin, Vera Simões, Lolly Hime, Vera Pacheco Jordão, os casais Wladimir Murtinho, Mário Fiorani, Piero Bondi, o fotógrafo Jacques Avadis e os embaixadores da Polônia e do Senegal.

Os suportes de cores, movimentos, sons e luzes integravam-se a modelos que trajavam os vestidos de Olly. Elas circulavam entre as obras da artista na sala de exposição do MAM-RJ, com movimentos diferenciados. 0 espetáculo movimentou o público e instigou seus espectadores a apreciar peças de vestuário com propostas estéticas, funcionais e relacionadas à cultura brasileira. Na reportagem, Olly realça as criações de vestuários brasileiros:

A confecção brasileira é boa, bonita e bem-feita - explicou Olly. Pode concorrer com qualquer tipo de manufatura estrangeira. Temos ótimos desenhistas, os nossos tecidos são bons e bonitos. Portanto, creio ter chegado a hora de não estremecer mais diante das etiquetas estrangeiras. (CORREIO DA MANHÃ, 1969, p.1)

A matéria do Correio da Manhã situa-se na última página do primeiro caderno, com um conteúdo curto com duas fotos do happening sucedido no MAM-RJ. A artista é exaltada em razão de sua proposta jovem. A beleza de suas padronagens em conjunto com a música eletrônica, os efeitos de luz e ambiente eram uma proposição nova no "plano de moda em desfile no País".

A produção jovem é uma das temáticas recorrentes das reportagens do Correio da Manhã, com destaque para conteúdos sobre os acontecimentos juvenis. Conforme Rainho (2014), em sua análise de séries fotográficas, o Correio da Manhã conservou o seu foco de atenção nas "figurações dos jovens" e na valorização de temas sobre o segmento etário, que durante os anos 1960 alcançaram protagonismo.

O jornal também destaca a proposta de Olly como nova para os desfiles brasileiros na década de 1960, entretanto, no próprio MAM-RJ, em 1967, na exposição Nova Objetividade Brasileira ${ }^{13}$, no coquetel de abertura foi apresentado o desfile de Solange Escoteguy, com sua coleção de roupas, a "NOB-NOB", música de Válter Smetak e coreografia de Renée, com três manequins, duas bailarinas e coreografia. A apresentação, realizada dois anos antes da exposição de Olly, é um exemplo que demonstra que a prática da exibição de vestuário artístico era recorrente.

Lembrando que essa não foi a primeira iniciativa de Olly em um desfile/apresentação. No Museu de Arte de São Paulo (MASP), em 13 de dezembro de 1966, Olly realizou uma exibição com 40 peças inspiradas nos motivos e objetos pré-colombianos, feitas com tecidos pintados à mão, por meio da técnica de batik. Os vestidos foram expostos por modelos que circulavam entre as obras do museu. Nessa proposta a artista aprimorou seus estudos em volumetria corporal, o que valorizou a apreciação dos tecidos em movimento.

\footnotetext{
${ }^{13}$ Nova Objetividade Brasileira foi uma exposição ocorrida no MAM-RJ, em 1967, que concentrou diferentes propostas das vanguardas nacionais, arte concreta, neoconcretismo, nova figuração. A mostra explorou a maior participação do espectador com as obras, temáticas políticas, éticas e sociais, proposições coletivas e novas formas de antiarte. Ressalta-se a produção de Hélio Oiticica na obra Tropicália, que comporta um jardim e até duas araras. Os sentidos (tato, olfato, visão e audição) são aguçados pelos penetrantes que estimulam a participação do espectador. Havia dois grandes, o menor, com uma espécie de caixa da solidão, e o outro, com maiores dimensões, que permitia ao visitante participar da obra.
} 
E mesmo no setor da indústria têxtil, os desfiles-show da Rhodia ${ }^{14}$, realizados na Fenit ${ }^{15}$, eram espetáculos que tinham uma narrativa, com personagens, locações específicas, músicas e temas relacionados com números musicais, de dança e esquetes teatrais. Os desfiles da Rhodia eram estratégias de publicidade de moda para a divulgação das novidades da indústria, que desenvolvia fios e fibras sintéticas para o mercado brasileiro. Os shows/ desfiles viajaram pelo Brasil e pelo exterior. Segundo Bonadio, as apresentações da Rhodia diferenciavam-se das demais de moda da Fenit:

\footnotetext{
Enquanto a organização da FENIT trazia para as passarelas modelos de costureiros internacionais, os desfiles da Rhodia primavam por incentivar a produção nacional, e reuniam numa mesma passarela peças assinadas por aqueles que eram então os grandes nomes da costura brasileira. (BONADIO, 2005, p.138)
}

O happening de Olly sucedido no MAM-RJ expõe o vestuário artístico em um espaço de arte graças a uma concepção de vanguarda e modernidade que está em convergência com os acontecimentos artísticos e os de moda, sobretudo nas estratégias de marketing da indústria têxtil. Na reportagem do Correio da Manhã a perspectiva de novidade é reconhecida no conjunto da composição apresentada, com projeções de slides, música eletrônica e modelos circulando entre as obras da artista. Como já mencionado, o evento de inauguração da exposição foi influenciado por manifestações ocorridas ao longo da década de 1960 na cena artística e de moda brasileira. Na figura 2, a modelo utiliza uma das peças inspiradas na temática Carajás, na qual os vestidos de Olly são expostos em uma exibição integrada entre objetos tridimensionais e planares.

\footnotetext{
${ }^{14}$ Rhodia S.A., filial da empresa francesa Rhône-Poulenc, estabelecida no país em 1919. A Rhodia obteve as patentes de fabricação de fios e fibras sintéticas no Brasil. A divulgação da nova matéria-prima foi realizada pela Divisão Têxtil da Rhodia e ocorreu com campanhas de publicidade por meio de produção fotográfica de moda para revistas e desfiles, com o objetivo de popularizar o uso do novo fio em tecidos e vestuários. Os eventos promovidos pela Rhodia utilizavam elementos da cultura do país com o intuito de criar uma "moda brasileira".

${ }^{15}$ Feira Nacional da Indústria Têxtil (Fenit), feira brasileira de produtos têxteis, coordenada pelo empresário Caio de Alcântara Machado, produzida em associação com o Sindicato das Indústrias Têxteis (Sinditêxtil). A Fenit divulgava os tecidos brasileiros e promovia as fibras naturais, em uma iniciativa da indústria têxtil para fomento da moda. A feira era aberta ao grande público com ingressos a preços populares. Nos anos de 1960, a Rhodia convidou estilistas brasileiros e artistas para desenhar e criar coleções com tecidos compostos por fios sintéticos. As apresentações de seus desfiles ocorreram anualmente entre 1963 e 1970, na FENIT.
} 


\section{FIGURA 2 - MODELO COM PEÇAS INSPIRADAS NA TEMÁTICA CARAJÁS}

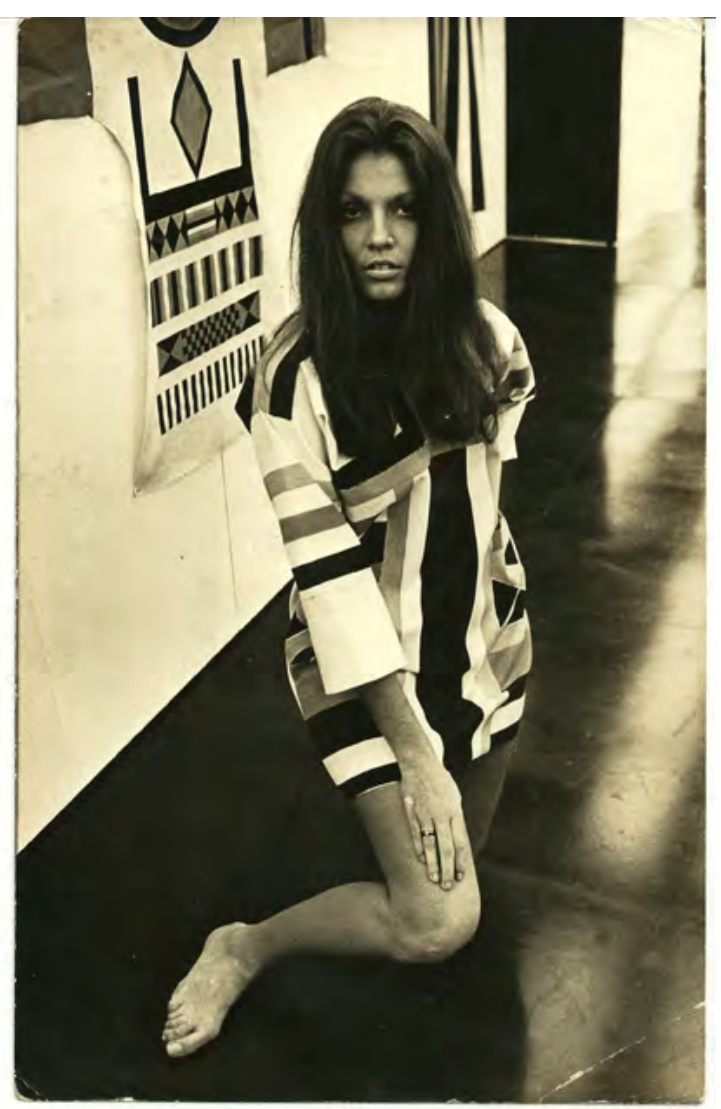

FONTE: Acervo Olly e Werner Reinheimer.

Na apreciação do happening, a contraposição de Campofiorito e da reportagem do Correio da Manhã mostra o olhar do crítico de acordo com uma visão conservadora de $O$ Jornal, principalmente em relação à produção artística vanguardista. Em sentido contrário, o Correio da Manhã visualiza na produção de Olly a criação de vestuários de vanguarda, uma obra jovem e inovadora em suas concepções expositivas de desfile e moda.

Na Revista de Domingo, do Jornal do Brasil ${ }^{16}$ (8/9/1969), e no Caderno Feminino, do jornal $O \operatorname{Dia}^{17}(17-18 / 8 / 1969)$, verifica-se a ênfase no uso das peças de Olly e seu lugar na

\footnotetext{
${ }^{16}$ Jornal do Brasil, instituído em 9 de abril de 1891 por Rodolfo de Sousa Dantas e Joaquim Nabuco. Na década de 1960, a reformulação do jornal diário foi realizada com a chegada de Alberto Dines, editor de 1961 a 1973. O jornal se reinseriu em novo momento de formação da opinião política do país e sua reestruturação gráfica impulsionou mudanças na imprensa carioca. No entanto, o jornal não perdeu sua característica liberal-conservadora.

${ }^{17} 0$ Dia, jornal carioca diário e matutino fundado em 5 de junho de 1951 por Antônio de Pádua Freitas. Em 26 de janeiro de 1964, o Dia se estruturou, aos domingos, com quatro cadernos: o primeiro com notícias gerais; o segundo com notícias esportivas; o terceiro com o Caderno Feminino; e o quarto com o Caderno de Diversões, este foi reformulado, desapareceu, e algumas de suas colunas foram para o Jornal da Tarde. O jornal detinha uma linha popular com destaque em assuntos policiais e cotidianos, entretanto defendeu o governo militar em muitas de suas ações.
} 
produção de vestuário da época em relação às criações de moda, e, em especial, na encomenda que a modelo Duda Cavalcanti fez das roupas da artista inspiradas nas referências indígenas Carajás, para exibi-las em Paris, quando foi à cidade filmar. Ela escolheu roupas que a diferenciavam da elegância das francesas. A Revista de Domingo destaca a esposa de Vladimir Murtinho e sua encomenda de peças à artista para sua viagem à Índia, em que fora representar o Brasil. Olly diz no Jornal do Brasil:

\footnotetext{
Eu sou brasileira, e o que me importa mais divulgar no estrangeiro são as cores, as formas e o espírito eminentemente brasileiros. Nesse ponto, meus vestidos inspirados nos bonecos dos índios Carajás são os mais importantes desta mostra. Os que lembram flores e pássaros são representativos enquanto coisa tropical e agradam sempre, mas há outros países tropicais. Os Carajás não: é Brasil puro. (JORNAL DO BRASIL, 1969, Revista de Domingo, p.7)
}

A reportagem na Revista de Domingo do Jornal do Brasil é de uma página inteira, localizada na página 7, de domingo, dia 7, e segunda-feira, dia 8 de setembro de 1969, intitulada O Brasil que Olly faz amar, com quatro fotos de modelos feitas no museu para a divulgação da exposição. As legendas explicam a origem da inspiração de Olly na produção indígena de bonecos de barro e seus grafismos e indicam possibilidades de uso dessas peças para a mulher moderna.

A exposição, sob o patrocínio do Itamarati, viajou à Europa e a alguns estados do Brasil. Olly declara na reportagem que não achava que pudesse ocorrer tal projeto em razão dos "problemas da moda no Brasil", semelhantes aos dos artistas que desenvolvem desenhos para grandes fábricas de tecidos brasileiras, e que a maioria prefere nesse mercado comprar "desenhos de tecidos no exterior" ou então copiar os das revistas. E ainda afirma: "0 desenhista brasileiro não tem mercado nesse setor. Por isso não tenho trabalho nele" (REVISTA DE DOMINGO, 1969, p. 7). A artista também confirma seu desejo de trabalhar para uma empresa realizando pesquisas no exterior. E do mesmo modo, levando o desenho e as cores brasileiras dessa empresa ao exterior. Nessa fala, observamos a intenção de Olly em atuar no setor de moda, entretanto, ela identifica a problemática da área de valorizar a produção estrangeira em detrimento da nacional, com fios naturais, desenhos de artistas e uma cultura diversa.

O texto da Revista de Domingo é finalizado com a informação de que irá acontecer um desfile semelhante ao dia o da inauguração para encerrar a exposição e que irá para a Europa no término da temporada. A data do desfile ainda seria anunciada e, graças ao sucesso da mostra, a data programada para a finalização foi prolongada.

Na figura 3, observa-se a divulgação da reportagem da exposição Vestidos-objeto, no MAM-RJ, no caderno de entrada do Jornal do Brasil de sábado, em que anunciava, com peças feitas por Olly, o título Arte Carajá é motivo para nova moda na Revista de Domingo em conjunto com outros assuntos que seriam apresentados nas páginas da revista semanal. A figura 4 é integrante da série de fotografias tiradas na exposição Vestidos-objeto. Algumas dessas imagens estavam presentes na reportagem da Revista de Domingo, do Jornal do Brasil, de domingo, 7, e segunda-feira, 8 de setembro de 1969, p.7. 


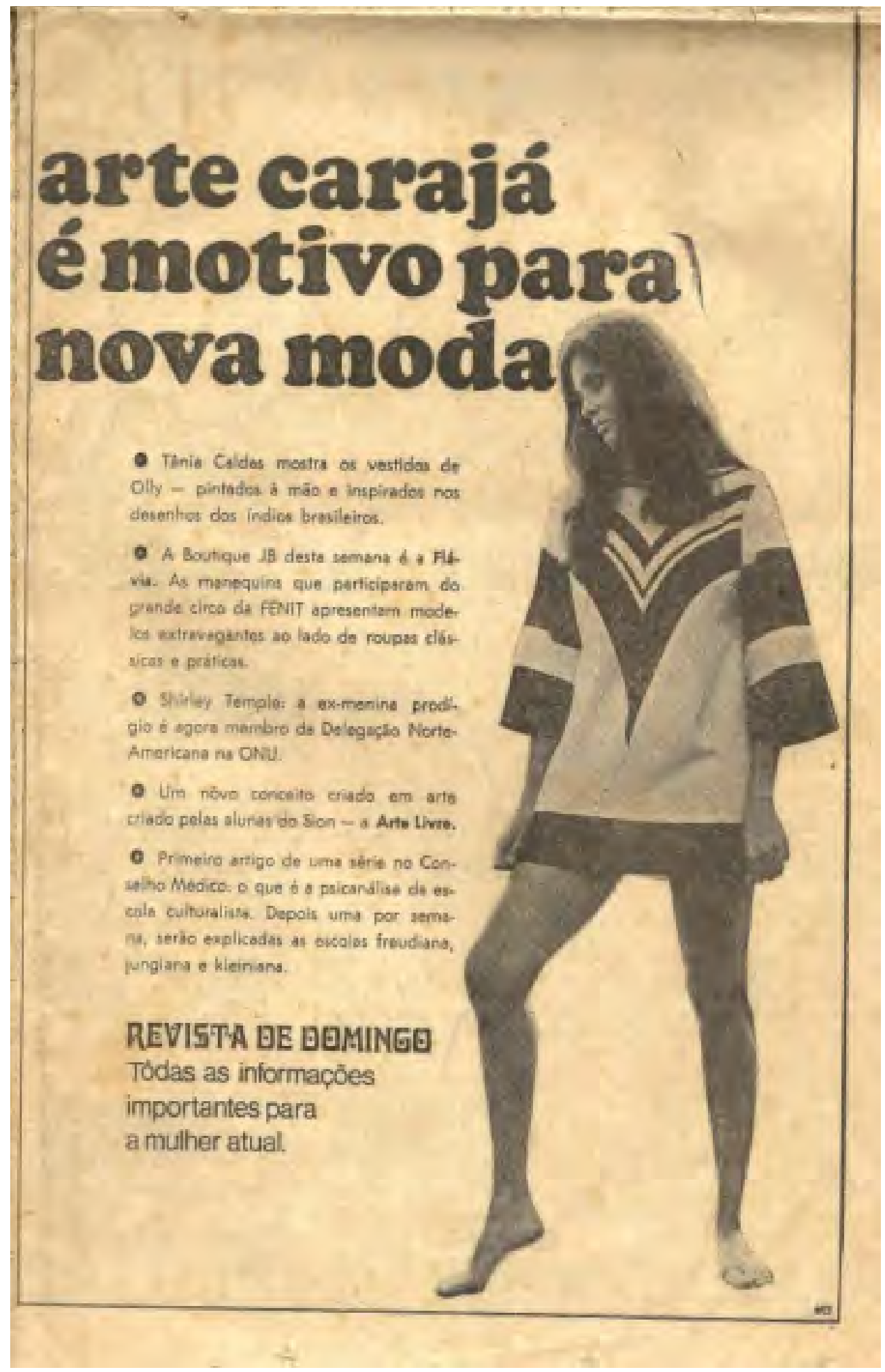

FONTE: Acervo Olly e Werner Reinheimer. Jornal do Brasil, 6 de setembro de 1969, 1ํ Caderno p.7. 
FIGURA 4 - FOTO INTEGRANTE DE SÉRIE DE FOTOGRAFIAS TIRADAS

NA EXPOSIÇÃO VESTIDOS-OBJETO, NO MAM-RJ

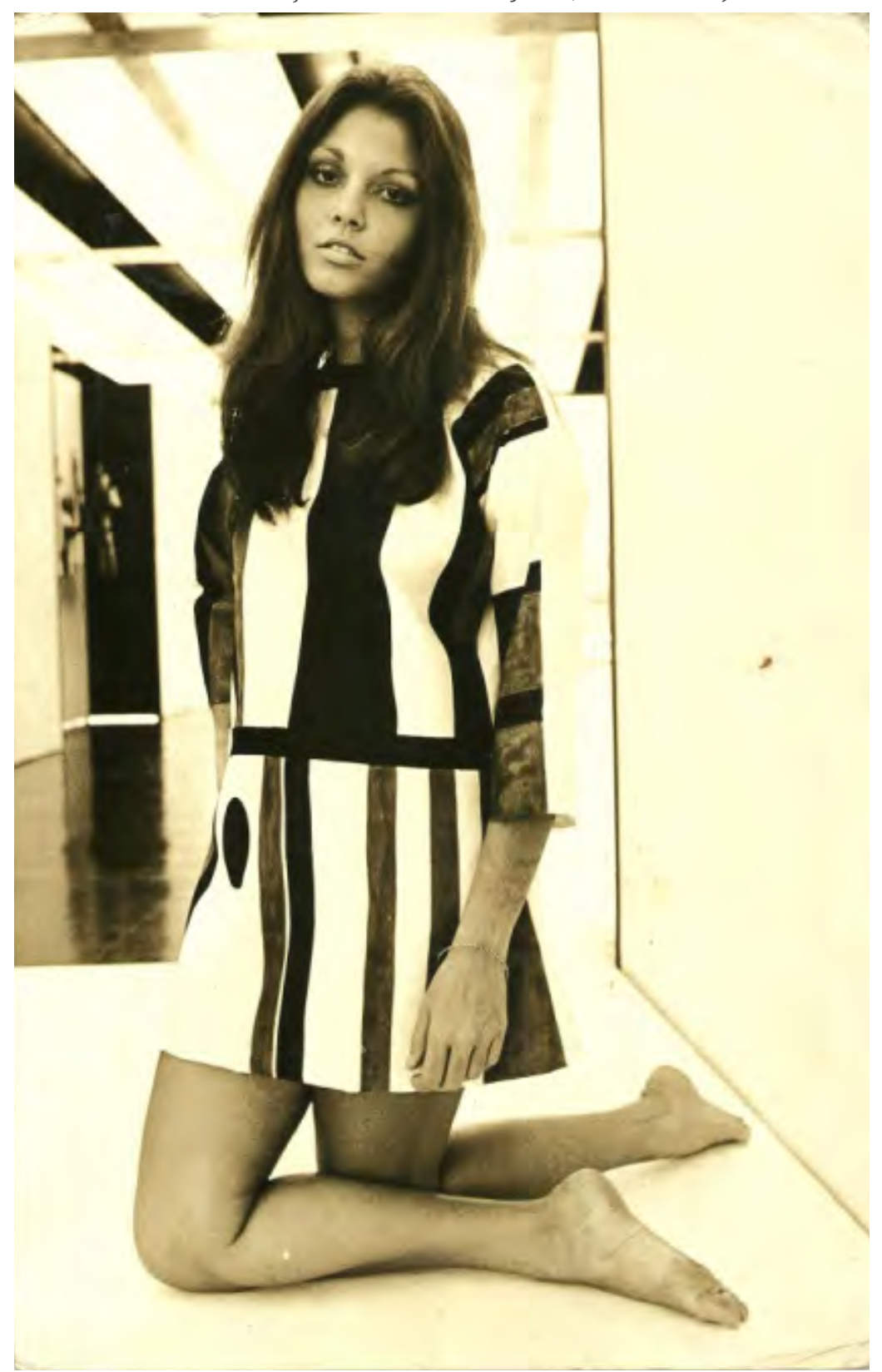

FONTE: Acervo Olly e Werner Reinheimer.

A reportagem do Caderno Feminino, do jornal O Dia, é de meia página e tinha três fotografias de destaque da modelo Tânia Galliez, usando as peças feitas por Olly, nos salões da exposição no MAM-RJ, nomeada "Os vestidos-objetos de Olly" e datada de 17 e 18 de agosto de 1969 (figura 5). 


\section{FIGURA 5 - A MODELO TÂNIA GALLIEZ NO CADERNO FEMININO DO JORNAL O DIA}

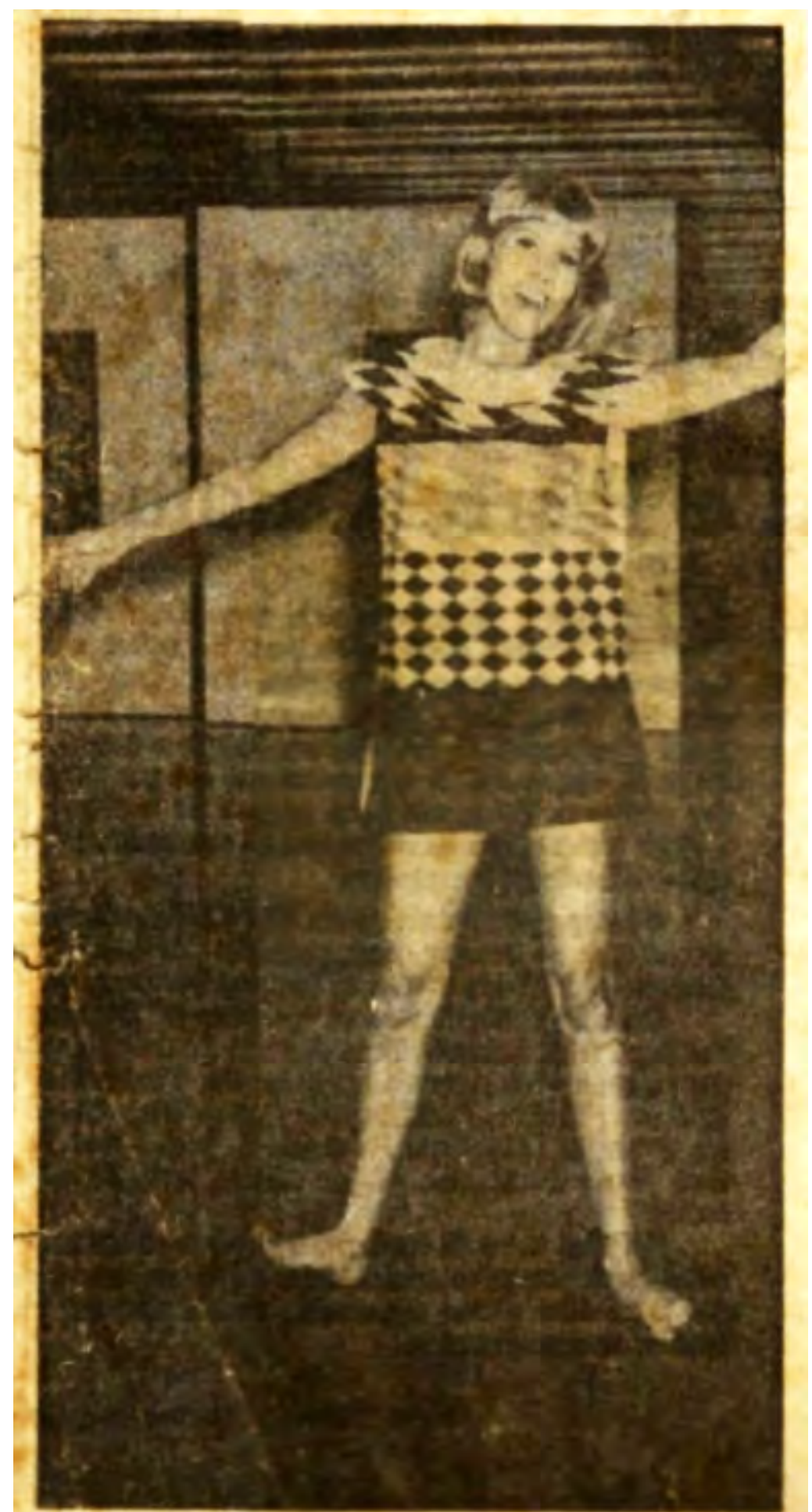

FONTE: Acervo Olly e Werner Reinheimer. Caderno Feminino, O Dia, 17 e 18 agosto de 1969, p. 2.

Olly também manifesta na coluna do Caderno Feminino seu apreço pelas confecções têxteis brasileiras e pela qualidade dos seus tecidos e critica a cópia das revistas estran- 
geiras. Tanto na Revista de Domingo, voltada para a leitura de entretenimento, quanto no Caderno Feminino, podemos identificar que o texto está direcionado para o evento de apresentação. Também é possível observar quem são as clientes de Olly e a sua inserção social, objetivando-se divulgar a produção da artista e seu espetáculo. Sobre esse assunto a reportagem pergunta à artista “Quem costuma comprar?”, e ela responde:

Geralmente artistas ou esposas de artistas, pessoal de TV, rádio, cinema, é um gênero mais para pessoas que gostam de usar coisas diferentes combinando com sua personalidade. "Minha especialidade é fazer roupa, o tecido, para o tipo da pessoa", diz ela. (O DIA, 1969, p. 2)

A temática brasileira, inspirada na cultura e na natureza, é explorada como um atributo em suas peças de interesse para encomendas estrangeiras e pessoas que irão ao exterior e desejam uma apresentação com roupas diferenciadas. Olly reproduzia suas peças em serigrafia, e no texto surge o questionamento de como a artista faz suas criações.

Com pincel, gravura, xilogravura com pedra, com metal, batik (técnica oriental), desenhos silk-screen - o que é novo. Faz também malha e pintura em acrílico (é uma máquina japonesa que faz todos os pontos), tendo já desfilado entre os mesmos um longo em malha transparente, cor de café, com duas voltas no pescoço, caindo com um xale tipo Isadora Duncan. (O DIA, 1969, p. 2)

A Revista de Domingo, do Jornal do Brasil, e o Caderno Feminino, do jornal O Dia, utilizam linguagem simples e conteúdo direcionado para o púbico feminino, salientando os usos e a criação da artista para o âmbito da moda. Usam fotos no formato de produções de moda com modelos posadas. Nas legendas, a orientação está em como a concepção de Olly pode ser aplicada nas composições de roupas e acessórios como novas referências de estampas, cores e volumes. Assim, o texto principal evidencia o processo criativo de Olly e sua inserção na produção brasileira de costura de vestuários e estampagem de tecidos.

As criações de Olly Reinheimer, seus objetos, retratam a trajetória de produção da artista, suas diversas fases e variadas técnicas, e constroem uma nova memória a partir de suas temporalidades, por meio da montagem de dados e de informações pesquisadas, em uma nova rede de construção simbólica e discursiva. Fica assim evidente, para o estudo de um objeto-vestuário em fontes visuais, a importância da atenção nas composições que significam e discursam sobre os mais variados posicionamentos culturais, artísticos, políticos e sociais.

Para Didi-Huberman (2013), as formas evidenciadas no passado sobrevivem e são transmitidas e modificadas no fluxo das imagens da história, ou no deslocamento temporal, o que constitui, a partir da história cultural, a compreensão das interações entre as imagens.

Do mesmo modo, os artefatos têxteis e vestíveis da produção de Olly são deslocados de seu aspecto funcional "do vestir". Assim, tornam-se uma imagem, a partir da interpretação integrada entre o passado e o presente, principalmente na análise da visualidade do objeto-vestuário que compunha a exposição Vestidos-objeto, realizada no MAM-RJ, em 1969. Dessa forma, as referências pré-colombianas e indígenas Carajás são recriadas e ressignifi- 
cadas pela artista como motivos visuais, não somente pelas novas proposições de grafismos aplicados nesses tecidos e vestuários, mas na conceituação estética de Olly em seus objetos artísticos e funcionais.

\section{Considerações finais}

O processo criativo de Olly era baseado em estudos esquemáticos de suas composições para tecelagem em escolha de cor, fundo e grafismo a partir da técnica. 0 desenvolvimento criativo da artista estava relacionado aos percursos de execução de suas criações por meio do tipo de artesania que seria utilizada. A artista desenvolve uma produção sem distinção entre arte "maior" e "menor", na década de 1960 e 1970, momento em que as fronteiras da arte não estão definidas, produzindo, assim, objetos cotidianos com "status" artístico. Isso é possível graças à concepção de modernidade em que esses itens são projetados a partir da integração das diversas técnicas. São elaborados como objetos com características, simultaneamente, funcionais e artísticas.

A exposição Vestidos-objeto, realizada no MAM-RJ, apresenta a artista Olly Reinheimer em uma produção em seu processo de experimentação que a caracterizou no cenário artístico e cultural. As diferentes opiniões sobre o trabalho da artista são notáveis nas interpretações de suas criações. Um exemplo está na coluna de Marc Berkowitz que valoriza a produção artística e funcional de Olly inserida em uma perspectiva de modernidade, na produção artesã e na experimentação de materiais, com o propósito de um resultado de elaboração criativa. Por outro lado, a Revista de Domingo, do Jornal do Brasil, estampa o evento com a foto de uma modelo que se apresentou na abertura da exposição vestida com uma peça de Olly, ressaltando a utilização de motivos visuais relacionados à arte Carajás para a moda do período. Desse modo, variadas leituras das análises realizadas pela mídia impressa à época confirmam a transitoriedade de sua atividade inventiva, inserida em um contexto artístico experimental e de formação da moda brasileira.

\section{Referências}

ARGAN, Giulio Carlo; FAGIOLO, Maurizio. Guia de História da Arte. Lisboa: Editorial Estampa, 1994.

ARGAN, Giulio Carlo. Walter Gropius e a Bauhaus. Rio de Janeiro: José Olympio, 2005.

ARGAN, Giulio Carlo. Arte moderna: do Iluminismo aos movimentos contemporâneos. São Paulo: Companhia das Letras. 2006.

ARGAN, Giulio Carlo. Arte Moderna na Europa: de Hogarth a Picasso. São Paulo: Companhia das Letras, 2010.

ARTE carajá é motivo para nova moda. Jornal do Brasil, 1ํㅜ caderno, 6 de setembro de 1969a. Capa da Revista de Domingo. 
BEDTCHE, Araceli. Antonio Bento e Romero Brest: o movimento abstrato como fluxo universal. Cadernos PROLAM/USP, v. 16, n. 30. 2017, p. 167-188. Disponível em: https:// doi.org/10.11606/issn.1676-6288. Acesso em: 12 jun. 2019.

BENTO, Antonio. Vestido-objeto de Olly. Última Hora, Rio de Janeiro, 21 de agosto de 1969.

BERKOWITZ, Marc. Vestidos-Objetos de Olly. Jornal do Commercio, Rio de Janeiro, 21 de setembro de 1969.

BONADIO. Maria Claudia. 0 fio sintético é um show! Moda, política e publicidade (Rhodia S.A. 1960-1970). 2005. 295f. Tese (Doutorado em História) - Instituto de Filosofia e Ciências Humanas, Universidade Estadual de Campinas,Campinas, 2005. Disponível em: http:// repositorio.unicamp.br/jspui/handle/REPOSIP/279891. Acesso em: 12 jun. 2019.

DIDI-HUBERMAN, Georges. 0 que vemos, o que nos olha. São Paulo: Editora 34, 1998.

DIDI-HUBERMAN, Georges. A imagem sobrevivente: história da arte e tempo dos fantasmas segundo Aby Warburg. Rio de Janeiro: Contraponto, 2013.

CAMPOFIORITO, Quirino. Vestidos-objetos. O Jornal, Rio de Janeiro, 6 de agosto de 1969.

CAMPOFIORITO, Quirino. Tecidos e vestidos de Olly. O Jornal, Rio de Janeiro, 14 de agosto de 1969.

CPDOC / FGV - VERBETES. Disponível em:

http://www.fgv.br/cpdoc/acervo/dicionarios/verbete-tematico. Acesso em: 11jun. 2019.

MENESES, Ulpiano T. Bezerra de. Fontes visuais, cultura visual, história visual. Balanço provisório, propostas cautelares. Revista Brasileira de História. São Paulo, v. 23, n. 45, 2003, p. 11-36.

MAM-RJ - Pinturas, Desenhos, Gravuras. Folder da exposição. Rio de Janeiro, 1952.

MAM-RJ - IDI. Programação de atividades. Rio de Janeiro, 1972.

MARCONDES, Gina. A Notícia, Rio de Janeiro, 9 de agosto de 1969.

MAURÍCIO, Jayme. Olly hoje no Museu. Correio da Manhã, Rio de Janeiro, p. 2, 2º Caderno, 6 de agosto de1969.

MORAIS, Frederico. Arte religiosa. Diário de Notícias, Rio de Janeiro, 27 de agosto de 1969. 
O BRASIL que Olly faz amar. Jornal do Brasil, Rio de Janeiro, Revista de Domingo, 7 de setembro de 1969 , p. 7.

OLLY no MAM. 0 Globo. Rio de Janeiro, 9 de agosto de 1969.

OLLY no Museu: happening da nova moda. Correio da Manhã, Rio de Janeiro, 7 de agosto de 1969, p. 1.

OS VESTIDOS-objeto de Olly. O Dia. Rio de Janeiro, Caderno Feminino, 17 e 18 de agosto de 1969, p. 2.

PONTUAL, Roberto. Dicionário das artes plásticas no Brasil. Texto: Mário Barata, Lourival Gomes Machado, Carlos Cavalcanti et al. Rio de Janeiro: Civilização Brasileira, 1969.

RAINHO, Maria do Carmo Teixeira. Moda e revolução nos anos 1960. Rio de Janeiro: Contra Capa, 2014.

REINHEIMER, Patricia. 0 universo de Olly, cores, formas, texturas: vida e obra de uma artista múltipla. 1999. 87f. Trabalho de Conclusão de Curso (Licenciatura em Educação Artística) - Faculdades Integradas Bennett, Rio de Janeiro, 1999.

SANT'ANNA, Sabrina Marques Parracho. Construindo a memória do futuro: uma análise da fundação do Museu de Arte Moderna do Rio de Janeiro. 2008. 225f.Tese (Doutorado em Ciências Humanas) - Instituto de Filosofia e Ciências Sociais, Universidade Federal do Rio de Janeiro, Rio e Janeiro, 2008. Disponível em: http://livros01.livrosgratis.com.br/cp073817. pdf. Acesso em: 7jun. 2019.

SANT'ANNA, Sabrina Marques Parracho. Wiederaufbau no Brasil: relações entre a escola de Ulm e o projeto pedagógico do MAM carioca. Sociologia \& Antropologia, Rio de Janeiro, v. 2, n. 3, jun. 2012, p. 183-201. Disponível em: http://www.scielo.br/scielo.php?script=sci_ arttext\&pid=S2238-38752012000300183\&lng=en\&nrm=iso. Acesso em: 12 jun. 2019.

VARELA, Elizabeth Catoia. Arte concreta além da Europa: Brasil-Argentina. Rio de Janeiro: MAM-RJ, 2017.

VESTIDO-OBJETO, objeto exportável. Jornal do Brasil, Rio de Janeiro, Caderno B, 13 de agosto de 1969 , p. 8. 